\title{
Complementary and Alternative Medicine: A Review on the Effects of Ginger, Cinnamon and Camellia Sinensis Leaf Tea in Diabetes
}

\author{
Massud Atta1 ${ }^{1}$, Shadi Jafari², Kareen Moore $^{2}$ \\ ${ }^{1}$ Coliseum Medical Center, Macon, Georgia \\ ${ }^{2}$ American University of Antigua, COM, Coolidge, Antigua
}

How to cite this paper: Atta, M., Jafari, S. and Moore, K. (2019) Complementary and Alternative Medicine: A Review on the Effects of Ginger, Cinnamon and Camellia Sinensis Leaf Tea in Diabetes. Journal of Diabetes Mellitus, 9, 126-136.

https://doi.org/10.4236/jdm.2019.93012

Received: June 5, 2019

Accepted: August 19, 2019

Published: August 22, 2019

Copyright $\odot 2019$ by author(s) and Scientific Research Publishing Inc. This work is licensed under the Creative Commons Attribution International License (CC BY 4.0).

http://creativecommons.org/licenses/by/4.0/ (c) (i) Open Access

\begin{abstract}
Diabetes mellitus is a chronic disease with a multitude of effects on different organ-systems. Its chronic nature makes it a challenging disease for patients to manage. Today, patients have access to many different types of conventional therapies for diabetes, each with a different mode of action and side effects. Despite the wide range of therapeutic agents available today, patients seek help from complementary and alternative medicine. The decision to use complementary and alternative medicine by patients stems from some of the harmful side effects of current conventional therapies, as well as their desire to find measures that will help them to manage their disease. Complementary and alternative medicine includes several modalities ranging from dietary components such as vitamins and herbal supplements to mind-body interventions such as yoga, meditation, and massage therapy. Here we review the use of complementary and alternative medicine including Ginger, Cinnamon, and Camellia sinensis leaf tea, and their effects on glycemic indices in diabetes.
\end{abstract}

\section{Keywords}

Diabetes Mellitus, Complementary and Alternative Medicine, Insulin, Hemoglobin A1c, Fasting Blood Glucose, Ginger, Cinnamon, Camellia Sinensis, Zingiber officinale, Cinnamomum zeylanicum, Ceylon cinnamon, Cinnamon cassia

\section{Introduction}

Diabetes mellitus (DM) is a chronic disease that affects millions of people worldwide. The lack of production of insulin from the beta-islet cells of the pancreas results in Type 1 Diabetes (DM1), also called Juvenile Diabetes. The body's 
inability to respond to insulin, known as insulin insensitivity, results in Type 2 Diabetes Mellitus (DM2). According to the World Health Organization (WHO), in $20148.5 \%$ of adults over the age of 18 suffer from DM, compared to $4.7 \%$ in 1980 [1]. In 2015, the International Diabetes Federation (IDF) recorded 415 million adults suffering from diabetes and estimated an increase to 642 million by 2040 [2]. According to the American Diabetes Association (ADA), diabetes is diagnosed by either Hemoglobin Alc (HbAlc) levels $\geq 6.5 \%$, Fasting Blood Glucose $(\mathrm{FBG}) \geq 126 \mathrm{mg} / \mathrm{dL}$ measured at 2 different times or a random blood glucose $\geq 200 \mathrm{mg} / \mathrm{dL}$ with symptoms of DM2 [3].

Despite the advancements in diabetes treatment, many patients seek alternative options due to various reasons. Complementary and alternative medicine (CAM) has gained popularity because of the possibilities it offers to patients. Complementary medicine refers to the use of products in adjunction to conventional treatments, while alternative medicine is the use of products as a substitute for conventional medicine [4]. The National Center for Complementary and Integrative Health (NCCIH) defines CAM as "a group of medical and health care systems, practices and products that are not presently considered to be part of conventional medicine" [2] [5].

A 2012 survey by the National Health Interview Survey (NHIS) reports the use of "dietary supplements other than vitamins and minerals" by $17.7 \%$ of Americans [4]. Diabetics compared to non-diabetics are 1.6 times more likely to try CAM and there are different contributing factors leading to this decision [6]. Medication side effects, cost of treatment, the ability to manage their illness, personal and cultural beliefs and disease progression despite the use of conventional medicines all play a role in why people choose CAM [2]. Dietary supplements such as vitamins, minerals, and herbal teas are amongst the common methods of CAM. There are also other types of CAM that focuses on mind-body health such as yoga, meditation, massage therapy, Tai Chi, acupuncture, music and art therapy [7]. In this paper, we focus on the following CAM and their role in the treatment of Diabetes: ginger, cinnamon and herbal tea.

\section{Ginger}

Ginger (Zingiber officinale), originated in Southeast Asia, is one of the most widely consumed spices around the world [8]. It has long been used as herbal medicine to treat a variety of ailments including nausea, indigestion, and common cold symptoms. Recently, studies have suggested that the antioxidant properties of ginger can also exert anticancer, anti-inflammatory, and anti-hyperglycemic effects [9]. Studies on diabetic-induced rats both in vitro and in vivo have shown that aqueous extracts of $Z$. officinale and polyphenol compounds in ginger can affect carbohydrate and lipid metabolism as well as insulin sensitivity. The mechanism by which ginger can exert these anti-diabetic effects is hypothesized to occur through the inhibition of several transcriptional pathways, lipid peroxidation, carbohydrate-metabolizing enzymes, and the activation of antioxidant en- 
zymes [10].

Ginger is speculated to reduce serum glucose levels through the activities of phenols, polyphenols, and flavonoids, which may inhibit intestinal glucosidase and amylase enzymes [11]. The antioxidants within ginger, including paradol and zingerone, can counteract lipid peroxidation [12] [13] [14]. These antioxidants might also decrease insulin resistance by improving glucose transport through the upregulation of the GLUT-4 transporter and insulin receptors, and enhance the activity of pancreatic beta islet cells secretory function [15] [16]. Other properties of ginger, including 6-gingerol and 6-shogaol, were found to increase insulin sensitivity by upregulating adiponectin and PPAR $\gamma$ [17].

Furthermore, studies conducted in streptozocin (STZ)-induced diabetic rats have been used to review the effects of ginger in diabetes. One study evaluated the anti-hyperglycemic effect of aqueous extract of $500 \mathrm{mg} / \mathrm{kg}$ ginger administered orally on a daily basis to rats in three different doses $(100,300,500 \mathrm{mg} / \mathrm{kg})$ for a period of 30 days. Results revealed a "dose-dependent anti-hyperglycemic effect with a decrease in plasma glucose levels by $38 \%$ and $68 \%$ on the $15^{\text {th }}$ and $30^{\text {th }}$ day, respectively" [18]. In another study, an aqueous extract of $500 \mathrm{mg} / \mathrm{kg}$ raw ginger was administered intraperitoneally daily to rats for a period of 7 weeks. The raw ginger was effective in lowering serum glucose, cholesterol and triacylglycerol levels in the ginger-treated diabetic rats compared with the control diabetic rats. The ginger treatment also resulted in a reduction in urine protein levels [19]. These studies suggest a direct effect of ginger and gingerols in the treatment of diabetes. However, further studies are needed to evaluate its safety uses and to clearly establish what dosage provides the greatest efficacy for the treatment of diabetes.

\section{Cinnamon}

Cinnamon, also called sweet wood (Greek origin), is obtained from the inner bark of a tropical evergreen tree [6]. Cinnamon has long been used in Indian Ayurvedic medicine, Unani System as well as 19th century American medicine to treat a variety of disorders [20]. The plant with over 250 species has two main varieties: Cinnamomum zeylanicum (CZ) or true/Ceylon cinnamon and Cinnamon cassia (CC) also known as Cinnamomum aromaticum/Chinese cinnamon [6] [20] [21] [22]. Cinnamon can be purchased in its quill form (cinnamon sticks), ground cinnamon powder, and aqueous extract. It contains constituents including; Cinnamaldehyde, Cinnamic acid, Cinnamyl acetate and eugenol which contribute to the therapeutic properties of cinnamon [23].

One main area of interest to researchers has been the effect of cinnamon in diabetes and its role in decreasing blood sugar levels. Cinnamon is thought to lower blood sugar by 1) Enhancing the activity of insulin receptor through autophosphorylation, 2) Promoting glucose uptake by enhancing the expression of GLUT-4, 3) Stimulating glycogenesis, 4) Inhibiting gluconeogenesis, and 5) Inhibiting the activity of enzymes such as pancreatic alpha-amylase and al- 
pha-glucosidase [21] [24]. GLUT-4, a family of transmembrane proteins involved in the uptake of glucose, is under the regulation of insulin. Insulin binds to insulin receptor (IR) which causes autophosphorylation of tyrosine residues on $\beta$-subunit of the receptor. This further activates a phosphatidylinositol $3 \mathrm{ki}$ nase signaling cascade that leads to expression of GLUT-4 on the cell surface [22] [25]. Cinnamtannin B1 and Cinnamaldehyde act like insulin to induce the IR. [22] [25]. Different studies done by Anderson et al. and Cao et al. demonstrated that polyphenols extracted from cinnamon have displayed similar activity to insulin [23].

The biomarkers used in these studies are fasting plasma glucose (FPG) and HbAlc. A study done by Khan et al. showed reduction in FPG, although no effect was observed on lowering HbA1c [20]. Similarly, a double-blind clinical trial study done by Mang et al. showed reduction in FPG and no effect on lowering HbA1c [20]. Liu et al. studied the effect of cinnamon along with chromium and carnosine in pre-diabetic patients for 4 months, which revealed a significant reduction in FPG levels [26]. There was no significant effect on HbAlc, as was demonstrated in a similar meta-analysis on a pre-diabetic population [26].

Even though some studies have demonstrated that cinnamon plays a role in lowering blood sugar, others have reported the contrary. Studies done by Vanschoonbeek et al., and Blevin et al. did not show significant effect of cinnamon on FPG or HbAlc [6]. In a study done by Talaei et al. the effect of $3 \mathrm{~g}$ of Cinnamon supplement for 8 weeks was studied in diabetic patients which did not show any significant effect on FPG, fasting insulin levels or HbA1c [27]. Another study by Steven et al. also did not demonstrate a decrease in FPG and HbAlc after using $1 \mathrm{~g}$ of cinnamon daily for three months [27]. The conflicting evidence of these studies can be based on factors such as sample size, duration of treatment, dosage form and formula, dose range, presence of conventional treatments, background of the patients including their lifestyle and diet regimen, presence of confounding factors and the quality of study design [20] [26] [27].

\section{Tea}

In this section, we will uncover the background of herbal teas, specifically the Camellia Sinensis leaf tea which is commonly used in Oolong tea. Camellia Sinensis leaves are commonly used in teas in India, China and Taiwan among others. Black tea, Oolong tea and Green tea all come from the Camellia Sinensis leaf but have different fermentation processes [28]. Black tea is fully fermented, while Oolong tea is partially fermented. One of the main components is the amount of Catechins which are believed to influence glucose metabolism [28]. The amounts of catechins vary per tea type, but Green tea has the most (at 30\% $40 \%$ per cup) and Black tea has the least ( $3 \%-10 \%$ per cup).

But how do these teas help lower sugar levels? According to Anderson and Polansky (2002) the Camellia Sinensis tea helps lower blood sugar by inducing insulin release [29]. Like sulfonylureas, it acts on the pancreas to release insulin 
thereby decreasing glucose in the bloodstream. Another possible mechanism of Camellia Sinensis tea is the catechin molecule that inhibits alpha-amylase, intestinal sucrase and alpha-glucosidase, all of which are involved in digestion of carbohydrates [28]. Another proposed mechanism is the increased expression of GLUT-4 transporter, which enhances glucose uptake by cells [30]. Lastly, the mechanism proposed by S. Khulood is Epigallocatechin Gallate (ECGC), found in Green tea, which are found to protect the beta-islet cells against cytokine damage [31].

Regardless of the mechanism, the majority of research studies and articles written about the Camellia Sinensis tea have shown that it provides relative improvement in glucose levels. While the efficacy may vary between each experiment, the general trend demonstrates that Camellia Sinensis tea helps reduce blood glucose levels. In a study, by Wu et al., fructose-only fed rats were examined by their levels of fasting glucose, insulin, blood pressure, GLUT-4, and insulin-stimulated glucose uptake. These rats were found to have elevated levels of FBG, insulin, and blood pressure while GLUT-4 and insulin-stimulated glucose uptake were decreased. However, when the rats were given Fructose/Green tea combination, an improvement in all of these biomarkers was found [30].

In another major study, 1898 subjects were used to compare the FBG levels in subjects consuming Green tea versus placebo/water [32]. This study showed a slight decrease in fasting blood glucose, which is regarded as significant improvement due to the large study population. Some of the studies may have shown improvement; however, studies with small sample sizes warrant further research to help establish more concrete results. For example, in a study by Nani et al., there were only 67 subjects that were evaluated for their research [33]. This study resulted in an average HbAlc decrease of $1.1 \%$. Furthermore, there was an average decrease of $1.37 \mathrm{mmol} / \mathrm{L}$ and $1.22 \mathrm{mmol} / \mathrm{L}$ in FBG at 8 and 12 weeks respectively. Although this may be considered significant, the low sample sizes warrant the need for further studies to be conducted on a greater scale.

\section{Discussion}

The prevalence of diabetes mellitus is high and rising worldwide due to the global increase in obesity and unhealthy lifestyles [9]. Type 2 diabetes accounts for more than $90 \%$ of diabetic cases and is associated with metabolic disorders of lipids and carbohydrates. Effective glycemic control in diabetic patients, including blood glucose levels and $\mathrm{HbAlc}$, is essential to reduce the risks of microvascular and macrovascular complications. These complications include cardiovascular disease, diabetic retinopathy, nephropathy, neuropathy, and fatty liver disease [2] [8]. In fact, diabetes is the leading cause of renal failure and the most preventable cause of blindness in the United States [1] [20]. Therefore, treatment of diabetes is imperative. Efforts have been made to create a wide range of medical treatment for diabetes including the use of Metformin, sulfonylureas, SGLT-2 inhibitors, DPP-4 Inhibitors and injectable insulin. However, the side effects of 
presently available hypoglycemic agents have led to continuous efforts to explore other effective agents for the management of diabetes.

CAM with anti-hyperglycemic effects is gaining increased popularity among diabetic patients. Herbal medicines with strong anti-inflammatory and hypoglycemic properties routinely generate attention for a possible role in the management of diabetes mellitus. Current scientific research shows that consumption of ginger may have a favorable impact on glycemic indices in patients with diabetes. One study found that consumption of ginger extract, either raw or cooked, reduced FBG to normal levels as effectively as treatment with anti-diabetic medication [34]. Another study showed that the consumption of $500 \mathrm{mg} / \mathrm{kg}$ of polyphenol ginger extracts for 28 days reduced FBG in STZ-treated diabetic rats [35]. In a double-blind placebo-controlled clinical trial, patients with DM2 received either placebo or $2000 \mathrm{mg}$ of ginger supplements per day for 10 weeks. Serum levels of FBG, total cholesterol, triacylglycerol, LDL-C, HDL-C, and HbAlc were analyzed. Ginger consumption significantly reduced serum levels of FBG and $\mathrm{HbAlc}$ in ginger-treated subjects compared to the placebo group [36]. In another clinical trial, diabetic patients were analyzed for changes in inflammatory markers, glycemic indices, and lipid profile after 12 weeks of supplementation with ginger. Improvements were most noticeable in glycemic indices and lowering of triglycerides with data supporting possible anti-inflammatory effects. Both $\mathrm{HbAlc}$ and insulin levels decreased, suggesting ginger may decrease insulin resistance and decrease serum glucose levels [37].

The heterogeneity among studies exploring the effects of cinnamon on glycemic control makes it difficult to draw a valid conclusion. Priyanga et al. demonstrated that $\mathrm{CZ}$ improved the metabolism of glucose after a standard oral glucose load in rats. This was attributed to its ability to enhance insulin signaling thereby increasing glucose uptake by cells [38]. Similar results reported by Qin et al. and other studies have indicated the increased phosphorylation of IR [38]. A study done by Crawford et al. resulted in reduction of HbAlc in patients receiving $1 \mathrm{~g}$ of cinnamon daily [6] [27]. In a random clinical trial by Anderson et al., a significant reduction in FPG as well as a 2-hr glucose load was found [6]. Per Costello, out of the five meta-analyses done on the effect of cinnamon on hyperglycemia, only three reported significant decrease in FPG and one in HbAlc [20]. While using cinnamon in some of these studies has shown benefit in lowering blood sugar levels, others have failed to replicate such results. Therefore, the NCCIH, ADA, and Canadian diabetes association (CDA) do not advocate for or support the use of cinnamon as an anti-diabetic therapy due to lack of sufficient evidence [20] [26].

Review of the literature regarding Camellia Sinensis tea consumption and its effect on glucose metabolism yield varying results. However, the majority of studies demonstrate lower blood glucose levels with the Camellia Sinensis tea. This is also demonstrated graphically in Figure 1 of the paper by Kondo et al. [32]. Per Maruyama et al. Green tea will help lower FBG, but only when consumed at 


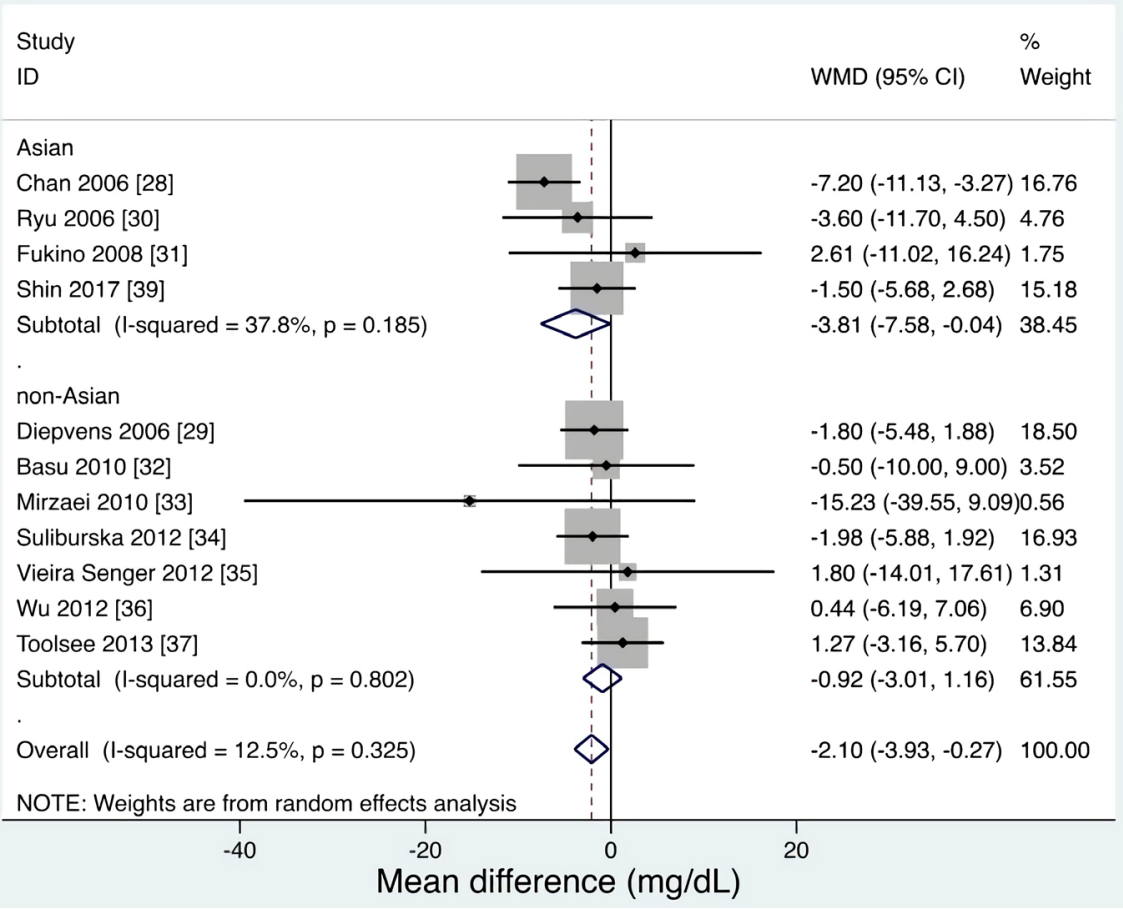

Figure 1. A graphic from a study by Kondo comparing other papers' results on the effect of tea on blood glucose.

higher concentrations [39]. In other studies, Green tea extract was found to lower FBG in diabetic patients with poor glycemic control [40]. However, a study by $\mathrm{Yu}$ et al., showed no difference between the use of Green tea, Green tea extract and placebo for HbAlc, fasting insulin and FBG [41]. Despite the number of studies conducted thus far, more research with greater sample sizes is required to find better evidence for the use of Camellia Sinensis tea in treating hyperglycemia.

Finally, complementary and alternative medicine can play a role in treating different conditions including diabetes. For example, Metformin, the first-line treatment drug fordiabetes, has its origins from a plant called Galegaofficinalis (French Lilac or Goat's Rue) [5]. It is possible that some of the CAM used today could have the potential to become therapeutic treatments for diabetes in the future. Even though CAM has the potential to benefit an array of illnesses, it is important to remember that there are limitations to these products. The lack of physician-patient communication with regard to the use of CAM products as well as the possible drug-drug interactions are some of those limitations [2]. Therefore, further research with improved design quality is recommended to better understand the role of complementary and alternative medicine in the treatment of diabetes.

\section{Conflicts of Interest}

The authors declare no conflicts of interest regarding the publication of this paper. 


\section{References}

[1] Diabetes. Who.int. https://www.who.int/news-room/fact-sheets/detail/diabetes

[2] Kesavadev, J., Saboo, B., Sadikot, S., et al. (2016) Unproven Therapies for Diabetes and Their Implications. Advances in Therapy, 34, 60-77.

https://doi.org/10.1007/s12325-016-0439-x

[3] American Diabetes Association (2016) Diagnosing Diabetes and Learning about Prediabetes. http://www.diabetes.org/diabetes-basics/diagnosis/?loc $=\mathrm{db}-$ slabnav

[4] Loren, D., Roscoe, R. and Shack, A. (2018) Complementary and Alternative Medicine for Diabetes. Canadian Journal of Diabetes, 42, 154-161.

https://doi.org/10.1016/j.jcjd.2017.10.023

[5] Medagama, A. and Bandara, R. (2014) The Use of Complementary and Alternative Medicines (CAMs) in the Treatment of Diabetes Mellitus: Is Continued Use Safe and Effective? Nutrition Journal, 13, 102. https://doi.org/10.1186/1475-2891-13-102

[6] Medagama, A. (2015) The Glycaemic Outcomes of Cinnamon, a Review of the Experimental Evidence and Clinical Trials. Nutrition Journal, 14, 108.

https://doi.org/10.1186/s12937-015-0098-9

[7] Johns Hopkins Medicine Complementary and Alternative Medicine. https://www.hopkinsmedicine.org/healthlibrary/conditions/complementary and al ternative medicine/home page-complementary and alternative medicine 85,P00185

[8] Li, Y., Tran, V.H., Duke, C.C. and Roufogalis, B.D. (2012) Preventive and Protective Properties of Zingiber officinale (Ginger) in Diabetes Mellitus, Diabetic Complications, and Associated Lipid and Other Metabolic Disorders: A Brief Review. Evidence-Based Complementary and Alternative Medicine, 2012, Article ID: 516870. https://doi.org/10.1155/2012/516870

[9] Daily, J.W., Yang, M. and Kim, S.S. (2015) Efficacy of Ginger for Treating Type 2 Diabetes: A Systematic Review and Meta-Analysis of Randomized Clinical Trials. Journal of Ethnic Foods, 2, 36-43. https://doi.org/10.1016/j.jef.2015.02.007

[10] Akash, M.S.H., Rehman, K., Tariq, M. and Chen, S. (2015) Zingiber officinale and Type 2 Diabetes Mellitus: Evidence from Experimental Studies. Critical Reviews in Eukaryotic Gene Expression, 25, 91-112. https://doi.org/10.1615/CritRevEukaryotGeneExpr.2015013358

[11] Shanmugam, K.R., et al. (2011) Neuroprotective Effect of Ginger on Antioxidant Enzymes in Streptozotocin-Induced Diabetic Rats. Food and Chemical Toxicology, 49, 893-897. https://doi.org/10.1016/j.fct.2010.12.013

[12] Kota, N., Panpatil, V.V., Kaleb, R., Varanasi, B. and Polasa, K. (2012) Dose Dependent Effect in the Inhibition of Oxidative Stress and Anti Clastogenic Potential of Ginger in STZ Induced Diabetic Rats. Food Chemistry, 135, 2954-2959. https://doi.org/10.1016/j.foodchem.2012.06.116

[13] Ghlissi, Z., Atheymen, R., Boujbiha, M.A., Sahnoun, Z., MakniAyedi, F., Zeghal, K., El Feki, A. and Hakim, A. (2013) Antioxidant and Androgenic Effects of Dietary Ginger on Reproductive Function of Male Diabetic Rats. International Journal of Food Sciences and Nutrition, 64, 974-978. https://doi.org/10.3109/09637486.2013.812618

[14] Shanmugam, K.R., Mallikarjuna, K., Nishanth, K., Kuo, C.H. and Reddy, K.S. (2011) Protective Effect of Dietary Ginger on Antioxidant Enzymes and Oxidative Damage in Experimental Diabetic Rat Tissues. Food Chemistry, 124, 1436-1442. https://doi.org/10.1016/j.foodchem.2010.07.104 
[15] Henriksen, E.J. (2006) Exercise Training and the Antioxidant Alpha-Lipoic Acid in the Treatment of Insulin Resistance and Type 2 Diabetes. Free Radical Biology \& Medicine, 40, 3-12. https://doi.org/10.1016/j.freeradbiomed.2005.04.002

[16] Mahluji, S., et al. (2013) Effects of Ginger (Zingiber officinale) on Plasma Glucose Level, HbAlc and Insulin Sensitivity in Type 2 Diabetic Patients. International Journal of Food Sciences and Nutrition, 64, 682-686. https://doi.org/10.3109/09637486.2013.775223

[17] Isa, Y., Miyakawa, Y., Yanagisawa, M., Goto, T., Kang, M.S., Kawada, T., Morimitsu, Y., Kubota, K. and Tsuda, T. (2008) 6-Shogaol and 6-Gingerol, the Pungent of Ginger, Inhibit TNF-alpha Mediated Downregulation of Adiponectin Expression via Different Mechanisms in 3T3-L1 Adipocytes. Biochemical and Biophysical Research Communications, 373, 429-434. https://doi.org/10.1016/j.bbrc.2008.06.046

[18] Abdulrazaq, N.B., Cho, M.M., Win, N.N., et al. (2011) Beneficial Effects of Ginger (Zingiber officinale) on Carbohydrate Metabolism in Streptozotocin-Induced Diabetic Rats. British Journal of Nutrition, 108, 1194-1201. https://doi.org/10.1017/S0007114511006635

[19] Al-Amin, Z.M., Thomson, M., Al-Qattan, K.K., et al. (2006) Antidiabetic and Hypolipidemic Properties of Ginger (Zingiber officinale) in Streptozotocin-Induced Diabetic Rats. British Journal of Nutrition, 96, 660-666.

https://doi.org/10.1079/BJN20061849

[20] Costello, R., Dwyer, J., Saldanha, L., Bailey, R., Merkel, J. and Wambogo, E. (2016) Do Cinnamon Supplements Have a Role in Glycemic Control in Type 2 Diabetes? A Narrative Review. Journal of the Academy of Nutrition and Dietetics, 116, 1794-1802. https://doi.org/10.1016/j.jand.2016.07.015

[21] Ranasinghe, P., Pigera, S., Premakumara, G., Galappaththy, P., Constantine, G. and Katulanda, P. (2013) Medicinal Properties of "True" Cinnamon (Cinnamomum zeylanicum). A Systematic Review. BMC Complementary and Alternative Medicine, 13, 275. https://doi.org/10.1186/1472-6882-13-275

[22] Taher, M., Abdul Majid, F. and Sarmidi, M. (2006) A Proanthocyanidin from Cinnamomum Zeylanicum Stimulates Phosphorylation of Insulin Receptor in 3T3-L1 Adipocytes. Jurnal Teknologi, 44, 53-68. https://doi.org/10.11113/jt.v44.385

[23] Visweswara, P. and Hua Gan, S. (2014) Cinnamon: A Multifaceted Medicinal Plant. Evidenced-Based Complementary and Alternative Medicine, 2014, Article ID: 642942. https://doi.org/10.1155/2014/642942

[24] Markey, O., McClean, C., Medlow, P., et al. (2011) Effect of Cinnamon on Gastric Emptying, Arterial Stiffness, Postprandial Lipemia, Glycemia, and Appetite Responses to High-Fat Breakfast. Cardiovascular Diabetology, 10, 78. https://doi.org/10.1186/1475-2840-10-78

[25] Nikzamir, A., Palangi, A., Kheirollaha, A., et al. (2014) Expression of Glucose Transporter 4 (GLUT4) Is Increased by Cinnamaldehyde in C2C12 Mouse Muscle Cells. Iranian Red Crescent Medical Journal, 16, e134264. https://doi.org/10.5812/ircmj.13426

[26] Liu, Y., Cotillard, A., Vatier, C., et al. (2015) A Dietary Supplement Containing Cinnamon, Chromium and Carnosine Decreases Fasting Plasma Glucose and Increases Lean Mass in Overweight or Obese Pre-Diabetic Subjects: A Randomized, Placebo-Controlled Trial. PLoS ONE, 10, e0138646. https://doi.org/10.1371/journal.pone.0138646

[27] Talaei, B., Amouzegar, A., Sahranavard, S., Hedayati, M., Mirmiran, P. and Azizi, F. (2017) Effects of Cinnamon Consumption on Glycemic Indicators, Advanced Gly- 
cation End Products, and Antioxidant Status in Type 2 Diabetic Patients. Nutrients, 9, 991. https://doi.org/10.3390/nu9090991

[28] Stote, K. and Baer, D. (2008) Tea Consumption May Improve Biomarkers of Insulin Sensitivity and Risk Factors for Diabetes. The Journal of Nutrition, 138, 1584S-1588S. https://doi.org/10.1093/jn/138.8.1584S

[29] Anderson, R. and Polansky, M. (2002) Tea Enhances Insulin Activity. Journal of Agricultural and Food Chemistry, 50, 7182-7186. https://doi.org/10.1021/jf020514c

[30] Wu, L., Juan, C., Hwang, L., Hsu, Y., Ho, P. and Ho, L. (2004) Green Tea Supplementation Ameliorates Insulin Resistance and Increases Glucose Transporter IV Content in a Fructose-Fed Rat Model. European Journal of Nutrition, 43, 116-124. https://doi.org/10.1007/s00394-004-0450-x

[31] Khulood, S.S. (2014) Hypoglycemic Property of Ginger and Green Tea and Their Possible Mechanisms in Diabetes Mellitus. The Open Conference Proceedings Journal, 5, 13-19. https://doi.org/10.2174/2210289201405010013

[32] Kondo, Y., Goto, A., Noma, H., Iso, H., Hayashi, K. and Noda, M. (2018) Effects of Coffee and Tea Consumption on Glucose Metabolism: A Systematic Review and Network Meta-Analysis. Nutrients, 11, 48. https://doi.org/10.3390/nu11010048

[33] Nani, D., SitiSuhaila, M., Faridah, M. and Wan Zahiruddin, W. (2016) The Effect of Gymnemasylvestre and Camellia sinensis on Patients with Type 2 Diabetes Mellitus. Health and the Environment Journal, 7, 1-19.

[34] Oludoyin, A.P. and Adegoke, S.R. (2014) Efficacy of Ginger (Zingiber officinale Roscoe) Extracts in Lowering Blood Glucose in Normal and High Fat Diet-Induced Diabetic Rats. American Journal of Food and Nutrition, 2, 55-58.

[35] Kazeem, M.I., Akanji, M.A., Yakubu, M.T. and Ashafa, A.O.T. (2013) Protective Effect of Free and Bound Polyphenol Extracts from Ginger (Zingiber officinale Roscoe) on the Hepatic Antioxidant and Some Carbohydrate Metabolizing Enzymes of Streptozotocin-Induced Diabetic Rats. Evidence-Based Complementary and Alternative Medicine, 2013, Article ID: 935486. https://doi.org/10.1155/2013/935486

[36] Khandouzi, N., Shidfar, F., Rajab, A., Rahideh, T., Hosseini, P. and Mir Taheri, M. (2015) The Effects of Ginger on Fasting Blood Sugar, Hemoglobin a1c, Apolipoprotein B, Apolipoprotein a-I and Malondialdehyde in Type 2 Diabetic Patients. Iranian Journal of Pharmaceutical Research, 14, 131-140.

[37] Haas, W. (2015) The Role of Ginger in Type 2 Diabetes Mellitus. Relias Media. https://www.reliasmedia.com/articles/135945-the-role-of-ginger-in-type-2-diabetes$\underline{\text { mellitus }}$

[38] Ranasinghe, P., Gunatilake, M., Gunapala, N., et al. (2012) Effects of Cinnamomum zeylanicum (Ceylon cinnamon) on Blood Glucose and Lipids in a Diabetic and Healthy Rat Model. Pharmacognosy Research, 4, 73. https://doi.org/10.4103/0974-8490.94719

[39] Maruyama, K., Iso, H., Sasaki, S. and Fukino, Y. (2009) The Association between Concentrations of Green Tea and Blood Glucose Levels. Journal of Clinical Biochemistry and Nutrition, 44, 41-45. https://doi.org/10.3164/jcbn.08-13

[40] Khan, F., Irshad, G., Hafiz, S. and Bari, M. (2012) Effect of Green Tea Polyphenols on HbA1C in Type 2 Diabetic Patients. Medical Forum Monthly, 23, 48-50.

[41] Yu, J., Song, P., Perry, R., Penfold, C. and Cooper, A. (2017) The Effectiveness of Green Tea or Green Tea Extract on Insulin Resistance and Glycemic Control in Type 2 Diabetes Mellitus: A Meta-Analysis. Diabetes \& Metabolism Journal, 41, 251. https://doi.org/10.4093/dmj.2017.41.4.251 


\section{Abbreviation List}

\begin{tabular}{|c|c|}
\hline Name & Abbreviation \\
\hline Diabetes Mellitus & $\mathrm{DM}$ \\
\hline Complementary and Alternative Medicine & CAM \\
\hline Type 1 Diabetes & DM1 \\
\hline Type 2 Diabetes & DM2 \\
\hline Hemoglobin A1C & $\mathrm{HbA1C}$ \\
\hline Fasting Blood Glucose & FBG \\
\hline National Center for Complementary and Integrative Health & NCCIH \\
\hline National Health Interview Survey & NHIS \\
\hline Streptozocin & STZ \\
\hline CinnamomumZeylanicum & $\mathrm{CZ}$ \\
\hline Cinnamon Cassia & $\mathrm{CC}$ \\
\hline Insulin Receptor & IR \\
\hline Fasting Plasma Glucose FPG & FPG \\
\hline Epigallocatechin Gallate & ECGC \\
\hline Glucose Transporter Type 4 & GLUT-4 \\
\hline Sodium-Glucose Co-transporter 2 & SGLT-2 \\
\hline Dipeptidyl peptidase & DPP-4 \\
\hline Low Density Lipoprotein & LDL \\
\hline High Density Lipoprotein & HDL \\
\hline Canadian Diabetes Association & $\mathrm{CAD}$ \\
\hline
\end{tabular}

